\title{
A New Possibility for Simultaneous Determination of Radioactive and Stable Isotopes in Environmental Samples by the Substoichiometric Method ${ }^{\dagger}$
}

\author{
Nagao IKEDA and Yoshihito TAKEDA \\ Institute of Chemistry, University of Tsukuba \\ Sakura-mura, Ibaraki Pref. 305, Japan \\ Received December 28, 1984
}

Key Words: substoichiometry, environmental radioactivity, stable isotope, cobalt -60

\section{Introduction}

The determinations of both the activity of a radionuclide and the amounts of its stable element are of ten necessitated in the studies on the behaviors of environmental radioactive species. It seems very convenient and advantageous, if the simultaneous determination of these two amounts could be possible.

In this paper, a possibility of application of the substoichiometric method is studied for this purpose, and the proposed principle is verified experimentally in the determination of ${ }^{60} \mathrm{Co}$ activity and the amounts of its stable isotope.

\section{Principle}

Two equal portions of the solution of the sample are taken. Each portion contains unknown amounts of the radionuclide (activity: $A_{\mathrm{x}}$ ) and the stable element (weight: $W_{\mathrm{x}}$ ) to be determined. To each portion, a known but different amount ( $W_{1}$ and $W_{2}$, respectively) of the stable element is added and mixed. From each solution, a definite part of the element to be determined is separated by using the definite but substoichiometric amount $(w)$ of the reagent which reacts with the element, and its activity ( $a_{1}$ and $a_{2}$, respectively) is measured. As the

†不足当量法による環境試料中の放射性および安定 同位体の同時定量の試み。池田長生, 竹田宜人 : 筑波大学化学系, 305 茨城県新治郡桜村天王台1$1-1$ 。 specific activity of the radionuclide in the separated part is unchanged from that in the solution before separation, the next equations hold.

$$
\begin{aligned}
& \frac{A_{\mathrm{x}}}{W_{\mathrm{x}}+W_{1}}=\frac{a_{1}}{w} \\
& \frac{A_{\mathrm{x}}}{W_{\mathrm{x}}+W_{2}}=\frac{a_{2}}{w}
\end{aligned}
$$

By solving the simultaneous equations, $A_{\mathrm{x}}$ and $W_{\mathbf{x}}$ are obtained as follows:

$$
\begin{aligned}
& A_{\mathrm{x}}=\frac{W_{2}-W_{1}}{w} \cdot \frac{a_{1} a_{2}}{a_{1}-a_{2}} \\
& W_{\mathrm{x}}=\frac{a_{2} W_{2}-a_{1} W_{1}}{a_{1}-a_{2}}
\end{aligned}
$$

As the amounts $W_{1}, W_{2}$ and $w$ can be maintained constant throughout a series of experiments, Eqs. (3) and (4) can be written as follows:

$$
\begin{aligned}
& A_{\mathrm{X}}=\alpha \cdot \frac{a_{1} a_{2}}{a_{1}-a_{2}} \\
& W_{\mathrm{X}}=W_{1} \cdot \frac{k a_{2}-a_{1}}{a_{1}-a_{2}}
\end{aligned}
$$

where $\alpha=\frac{W_{2}-W_{1}}{w}$ and $k=\frac{W_{2}}{W_{1}}$.

Thus, $A_{\mathrm{x}}$ is proportional to $a_{1} a_{2} /\left(a_{1}-a_{2}\right)$ and independent of $W_{\mathbf{x}}$, while $W_{\mathbf{x}}$ is proportional to $\left(k a_{2}-a_{1}\right) /\left(a_{1}-a_{2}\right)$ and independent of $A \mathbf{x}$. Accordingly, plotting $A_{\mathrm{x}} v s . a_{1} a_{2} /\left(a_{1}-a_{2}\right)$ or $W_{\mathrm{x}}$ vs. $\left(k a_{2}-a_{1}\right) /\left(a_{1}-a_{2}\right)$ should give a straight line on the linear graphic paper.

\section{Experimental}

A $100 \mathrm{~m} l$ portion of the mock sample solution, in which $200-2000 \mathrm{cpm}$ of ${ }^{60} \mathrm{Co}$ and $20-200 \mu \mathrm{g}$ of stable $\mathrm{Co}(\mathbb{I})$ were contained, was taken in 
a $200 \mathrm{~m} l$ separatory funnel and $5 \mathrm{~g}$ of magnesium chloride was added. After addition of $510 \mu \mathrm{g}$ $\mathrm{Co}^{2+}\left(W_{1}\right)$ of cobalt chloride and the aqueous solution of $1.50 \mathrm{mg}(w)$ of sodium diethyldithiocarbamate, the solution was shaken with $20 \mathrm{~m} l$ of benzene. The activity $\left(a_{1}\right)$ of the organic layer was measured with a liquid scintillation counting system.

The second measurement of activity $\left(a_{2}\right)$ was carried out with another $100 \mathrm{~m} l$ portion of the mock sample solution in the similar way, by adding $850 \mu \mathrm{g} \mathrm{Co}{ }^{2+}\left(W_{2}\right)$ of cobalt chloride solution.

\section{Results}

An example of the linear relationship between activity $A_{\mathrm{x}}$ and $a_{1} a_{2} /\left(a_{1}-a_{2}\right)$ is shown in Fig. 1. In the similar way, the weight of stable cobalt $W_{\mathbf{x}}$ shows fairly good linearity with respect to $\left(k a_{2}-a_{1}\right) /\left(a_{1}-a_{2}\right)$.

By using these calibration curves, some mock samples containing picocurie level of ${ }^{60} \mathrm{Co}$ and $100 \mu \mathrm{g}$ level of stable cobalt were analysed. The results are shown in Table 1. Considering that significant figures are 2 degits, the observed values are in fairly good concordance with taken ones.

The advantages of this method are: 1) The procedure is simple and rapid. 2) By using the calibration curves or the constant values of the slope for each straight line, the accurate amounts of $W_{1}, W_{2}$ and $w$ are not necessary to be known. Only necessary are to keep the volumes of the stable element solution added and reagent solution constant throughout a series of experiments, and to measure the activities $a_{1}$
Table 1 Simultaneous determination of ${ }^{80} \mathrm{Co}$ and stable cobalt

\begin{tabular}{cc||cc}
\hline \multicolumn{2}{c||}{ Amounts taken } & \multicolumn{2}{c}{ Amounts observed } \\
\hline \begin{tabular}{cc||cr}
${ }^{60} \mathrm{Co}$ \\
$(\mathrm{Bq})$
\end{tabular} & $\begin{array}{c}\text { Stable Co } \\
(\mu \mathrm{g})\end{array}$ & $\begin{array}{c}{ }^{60} \mathrm{Co} \\
(\mathrm{Bq})\end{array}$ & $\begin{array}{c}\text { Stable Co } \\
(\mu \mathrm{g})\end{array}$ \\
\hline 23 & 170 & 25 & 160 \\
34 & 57 & 37 & 69 \\
46 & 110 & 50 & 120 \\
\hline
\end{tabular}

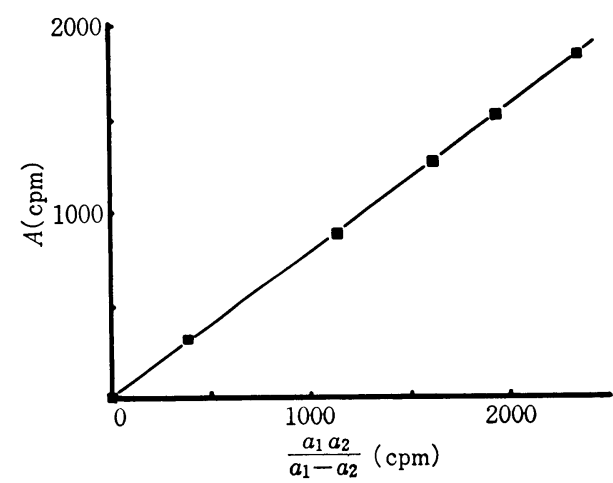

Fig. 1 Linear relationship between $A \mathbf{x}$ and $a_{1} a_{2} /\left(a_{1}-a_{2}\right)$.

and $a_{2}$ correctly. 3) The measurements of the chemical yield of the stable carrier are unnecessary.

The method seems suitable for the routine and many samples analyses for radioactive and stable cobalt in such environmental samples as marine deposits and biological ashes, etc.

Part of the expense of this study was defrayed by a grant from the Ministry of Education of Japan, to which the authors' thanks are due. 